\title{
Mycorrhizal co-invasion and novel interactions depend on neighborhood context
}

\author{
Holly V. Moeller,${ }^{1,4}$ Ian A. Dickie, ${ }^{2,3}$ Duane A. Peltzer, ${ }^{3}$ and Tadashi Fukami ${ }^{1}$ \\ ${ }^{1}$ Department of Biology, Stanford University, Stanford, California 94305 USA \\ ${ }^{2}$ Bio-Protection Research Centre, Lincoln University, Lincoln 7640 New Zealand \\ ${ }^{3}$ Landcare Research, Lincoln 7640 New Zealand
}

\begin{abstract}
Biological invasions are a rapidly increasing driver of global change, yet fundamental gaps remain in our understanding of the factors determining the success or extent of invasions. For example, although most woody plant species depend on belowground mutualists such as mycorrhizal fungi and nitrogen-fixing bacteria, the relative importance of these mutualisms in conferring invasion success is unresolved. Here, we describe how neighborhood context (identity of nearby tree species) affects the formation of belowground ectomycorrhizal partnerships between fungi and seedlings of a widespread invasive tree species, Pseudotsuga menziesii (Douglas-fir), in New Zealand. We found that the formation of mycorrhizal partnerships, the composition of the fungal species involved in these partnerships, and the origin of the fungi (co-invading or native to New Zealand) all depend on neighborhood context. Our data suggest that nearby ectomycorrhizal host trees act as both a reservoir of fungal inoculum and a carbon source for late-successional and native fungi. By facilitating mycorrhization of $P$. menziesii seedlings, adult trees may alleviate mycorrhizal limitation at the $P$. menziesii invasion front. These results highlight the importance of studying biological invasions across multiple ecological settings to understand establishment success and invasion speed.
\end{abstract}

Key words: biological invasion; Douglas-fir; ectomycorrhizal fungi; mutualisms; plant-soil interactions; Pseudotsuga menziesii.

\section{INTRODUCTION}

Mutualistic interactions can prevent or facilitate biological invasions (Richardson et al. 2000, Nuñez et al. 2009, Spence et al. 2011) and determine the lag-phase between a species' introduction and subsequent invasion (Hallett 2006). Successful establishment and invasion of woody plants may be particularly sensitive to belowground symbiont availability, because many of these woody plant species depend on mutualistic microbes like mycorrhizal fungi and nitrogen-fixing bacteria (Nuñez and Dickie 2014). In fact, recent research has revealed that both co-invasion of nonnative mutualist species and novel associations with native species determine invasion success (Pringle et al. 2009, Dickie et al. 2010, Nuñez and Dickie 2014, Wood et al. 2015). For example, ectomycorrhizal pines appear to invade only when co-invading exotic or cosmopolitan fungi are available (Nuñez et al. 2009, Dickie et al. 2010, Hynson et al. 2013, Hayward et al. 2015), though introduced trees may form novel associations with native fungi as adults (Parladé et al. 1995, Jairus et al. 2011, Trocha et al. 2012, Bahram et al. 2013). These studies also

Manuscript received 10 December 2014; revised 19 February 2015; accepted 24 February 2015. Corresponding Editor: J. D. Hoeksema.

${ }^{4}$ E-mail: hollyvm@alum.mit.edu demonstrate that the importance of co-invasion in conferring invasion success is variable among studies or taxa, but the reasons for this are unresolved.

The apparent importance of co-invasion to some trees may have arisen in part because individual studies tend to focus on invasion in only a single environmental context. For example, few studies have identified the mycorrhizal associates of ectomycorrhizal trees invading into native forests. However, context may be important to invasion because neighboring ectomycorrhizal hosts can influence the ectomycorrhizal communities of seedlings, regardless of whether the neighboring host is of the same (Simard et al. 1997, Dickie and Reich 2005, Nara 2006) or of a different (Horton et al. 1999, Nara and Hogetsu 2004, Bogar and Kennedy 2013) species as the seedling. This neighborhood effect may be caused by an actively growing common mycorrhizal network (Fleming 1983, Newman 1988, Simard and Durall 2004) or by a soil spore bank (Ashkannejhad and Horton 2006, Collier and Bidartondo 2009). Furthermore, plantations of introduced trees may be more likely to host native ectomycorrhizal fungi when native ectomycorrhizal hosts are nearby (Bahram et al. 2013). This suggests that the neighborhood context into which an introduced tree is self-seeding should determine the availability of fungal partners and, possibly, its likelihood of becoming invasive. 
In this study, we examined the effect of neighborhood context on ectomycorrhiza formation during nonnative tree invasion using a study system in which multiple species of nonnative conifers (Dickie et al. 2010, Essl et al. 2010, Nuñez and Dickie 2014) and associated ectomycorrhizal fungi (Chu-Chou and Grace 1987, Davis et al. 1996) have been introduced. We focused on the North American tree Pseudotsuga menziesii (Douglas-fir) which, in its native range, is a fungal generalist associating with $\sim 2000$ species of ectomycorrhizal fungi (Trappe 1962, 1977). Despite this partnership flexibility, $P$. menziesii was initially postulated to be relatively less invasive than Pinus species in New Zealand because of a lack of fungal mutualists (Davis et al. 1996, Dickie et al. 2010). However, subsequent to the introduction of compatible ectomycorrhizal fungi, $P$. menziesii has become an invasive species of conservation concern, able to establish both in grasslands and beneath the canopy of native Fuscospora (southern beech) forests (Dickie et al. 2010, Froude 2011; see Plate 1).

Given the long history of both deliberate and accidental fungal introductions to New Zealand, the high diversity of native ectomycorrhizal fungal taxa, and the partnership flexibility of $P$. menziesii, we expected fungal associations to vary by neighborhood. We evaluated mycorrhization of $P$. menziesii seedlings in three neighborhood contexts: (1) P. menziesii plantation, i.e., in the presence of established, conspecific ectomycorrhizal host trees; (2) Fuscospora cliffortioides canopy, i.e., in the presence of native, ectomycorrhizal host trees; and (3) grasslands, i.e., in the absence of adult ectomycorrhizal hosts. We tested three hypotheses about the presence, composition, and origin of seedling ectomycorrhizas in these contexts. First, we hypothesized that $P$. menziesii seedlings would be fungus limited (i.e., no compatible fungi would be available to form ectomycorrhizas) in grasslands in which established ectomycorrhizal hosts were absent, but would not be fungus limited where other ectomycorrhizal plants were present, regardless of plant identity. Second, we hypothesized that the richness and composition of the ectomycorrhizal fungal community on $P$. menziesii seedlings would differ by neighborhood context due to the variable presence of other ectomycorrhizal host plants and compatibility with associated fungi. Third, we hypothesized that the origin of fungal partners would explain this context dependence such that co-invading fungi would dominate in all habitats, but associations with native fungi would occur as an important component exclusively in native forest neighborhoods.

We tested these hypotheses by collecting self-established P. menziesii seedlings from each of the three neighborhood contexts and quantifying their ectomycorrhizal communities. This allowed us to determine the fungal associates of $P$. menziesii where seedlings were already invading. We also used a greenhouse soil

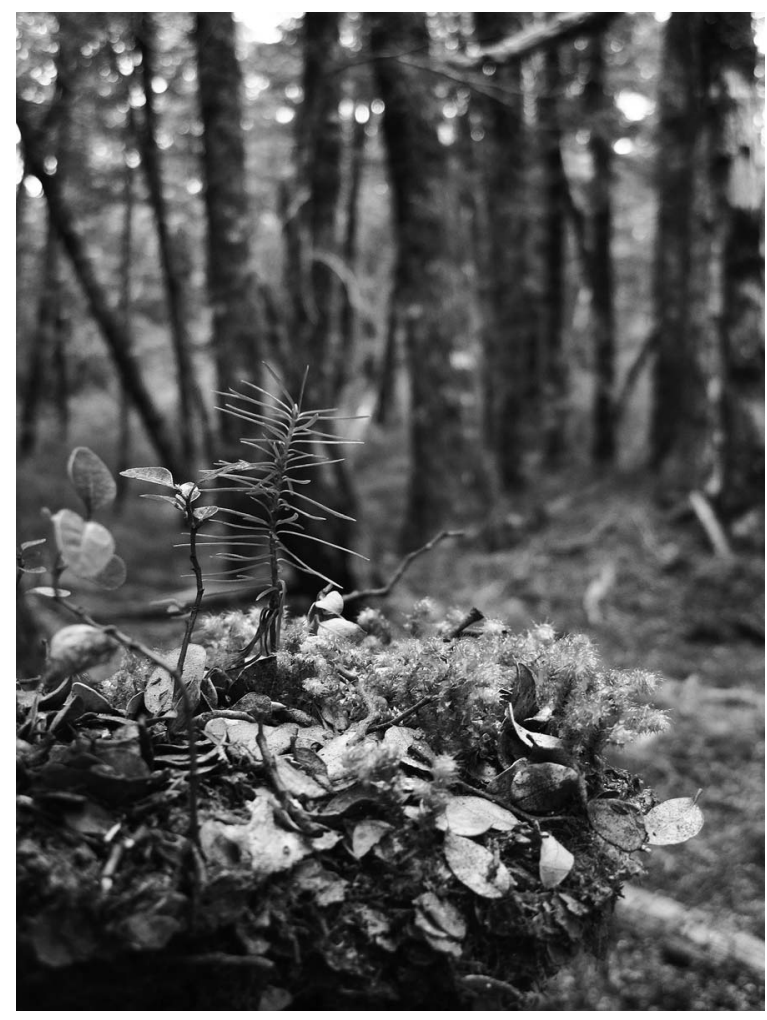

Plate 1. An invasive Pseudotsuga menziesii (Douglas-fir) seedling grows alongside native Fucospora cliffortioides seedlings in under native $F$. cliffortioides canopy in Cora Lynn on the South Island of New Zealand. Native forests adjacent to $P$. menziesii plantations show increasing evidence of both tree and ectomycorrhizal fungal invasions. Photo credit: H. V. Moeller, February 2012.

bioassay to control for any potential differences among field sites. For the bioassay, we planted bait P. menziesii seedlings in field-collected soils from both invaded and uninvaded sites and measured mycorrhization of these seedlings by soil fungi. We used a greenhouse approach because planting potentially invasive tree seedlings directly into the field was neither feasible nor ethical, given that grassland and native forest sites were generally within or adjacent to conservation areas. The greenhouse approach also differs from the field survey by focusing on "early-stage" fungi, capable of forming mycorrhizas on seedlings in the absence of active carbon subsidies from mature trees (Deacon et al. 1983, Simard et al. 1997). Seedlings may be able to establish and persist for some time without ectomycorrhizas and may potentially accumulate symbionts over time (Dickie et al. 2002, Collier and Bidartondo 2009). The consequence of poor initial mycorrhization is widely reported to reduce nutrient uptake and plant growth, thus making seedlings less competitive against surrounding vegetation and more vulnerable to pathogens during the establishment phase (Marx 1972). 


\section{Materials And Methods}

Invasive seedling survey

We determined the community of ectomycorrhizal fungi on invading Pseudotsuga menziesii seedlings within each of five sites located in the central South Island of New Zealand (Appendix: Fig. A1). Mixtures of grassland and forest vegetation located in close proximity are common in New Zealand; here, we used this field system to provide different contexts to test our hypotheses about plant-fungal interactions during invasion. We selected sites that had an established $P$. menziesii plantation $>20$ years in age, $P$. menziesii seedlings naturalized from this source, and both a native forest (southern beech, Fuscospora cliffortioides (Hook.f.), previously Nothofagus solandri [Heenan and Smissen 2013]) and a grassland within $1 \mathrm{~km}$ of the mature $P$. menziesii plantation. Detailed site histories are not known, but grasslands in our study system were originally native forests that were transformed to grasslands through anthropogenic fires, initially by Māori ca. 1300s and subsequently by 19th century European settlers (Perry et al. 2014). Nonnative trees were established from the early 1900s into such grasslands, and this introduction effort is ongoing. Native forests were all old growth, with no history of timber harvesting. At each site, we excavated intact $P$. menziesii seedlings with their entire root systems during the austral summer (February 2012). For two of our sites, we were unable to find any naturalized $P$. menziesii in adjacent grasslands.

Within each of the three neighborhoods (i.e., grassland, or forest dominated by either $F$. cliffortiodes or $P$. menziesii), we recorded the spatial locations (Garmin GPSMAP 62s, Schaffhausen, Switzerland) of and collected at least 15 seedlings between the ages of 1 and 15 years (assessed by whorl counts). To control for the influence of neighboring common mycorrhizal networks, we collected only seedlings that were at least $30 \mathrm{~m}$ from the edge of boundaries with other neighborhoods (Cline et al. 2005, Dickie et al. 2012). Seedlings were stored in plastic bags at $4^{\circ} \mathrm{C}$ for up to 10 days until processing. During processing, seedling root systems were washed clean of soil with tap water, and then all root tips were inspected under a dissecting microscope for the presence of a fungal mantle. For each seedling, ectomycorrhizal root tips were grouped into morphotypes based on fungal mantle color, structure, and hydrophobicity, and at least three individual root tips of each morphotype from each seedling were used to identify fungi via DNA extraction and sequencing. Following processing, seedling root and shoot systems were dried separately at $60^{\circ} \mathrm{C}$ for 72 hours to obtain dry mass.

\section{Soil bioassay}

We collected bioassay soils from under each of the three neighborhoods at each of eight study sites (Appendix: Fig. A1). We used the same selection criteria for sites as was used in the field survey, but included neighborhoods regardless of whether invasive $P$. menziesii seedlings were present. Ten soil cores $(64 \mathrm{~mm}$ in diameter, $100 \mathrm{~mm}$ deep) were collected from each neighborhood within each site in March 2012, and retained intact within PVC pipe. One additional set of 10 grassland cores was taken from the lower Cora Lynn study site to provide an additional invaded grassland sample. Sampling locations of cores were determined using both random distance (between 0.5 and $15 \mathrm{~m}$ ) and bearing from each previous core. The upper $5 \mathrm{~mm}$ of the soil core was trimmed away to remove herbaceous plants. The bottom of the core was secured using nylon mesh. Cores were wrapped in plastic and stored at $4^{\circ} \mathrm{C}$ for up to two weeks prior to the bioassay trial. Additional soil samples (100-mm depth) were taken adjacent to each core, pooled across all neighborhood types and sites, homogenized, autoclaved (30 minutes, $121^{\circ} \mathrm{C}, 103 \mathrm{kPa}$ [15 pounds per square inch]), and subsequently used for bioassay controls.

Intact soil cores were placed onto individual trays to prevent splashing or mixing of water between cores, and were randomly arranged in a greenhouse. Twenty-four additional control pots were added to the study: 14 PVC pipe segments filled with autoclaved soil, and 10 PVC pipe segments filled with autoclaved perlite. All soil cores were deliberately waterlogged in the greenhouse for a period of five consecutive days to overcome hydrophobicity in the soil. Two P. menziesii seedlings (germinated approximately two weeks beforehand from seed sourced from New Zealand Tree Seeds, Rangiora, New Zealand) were planted in each intact core. A total of 548 seedlings ([8 sites $\times 3$ neighborhood contexts +1 additional grassland] $\times 10$ cores $\times 2$ seedlings per core + 24 control pots $\times 2$ seedlings per control) were maintained under natural light and watered twice weekly.

Seedlings were harvested in November 2012 after 8 months of growth, and mortality was recorded. Root systems were washed of adhering soil and inspected under a dissecting microscope. Each root tip was inspected for an ectomycorrhizal mantle, and up to 8 mycorrhizal root tips were randomly selected for DNA extraction and sequencing. Where fewer than 20 ectomycorrhizal root tips were available $(76 \%$ of ectomycorrhizal seedlings), only 6 tips were sampled for DNA extraction.

\section{Fungal identification and data analysis}

We extracted DNA using Extraction Solution and Neutralization Solution B (Sigma-Aldrich Company, St. Louis, Missouri, USA) following the protocol of Avis et al. (2003) as modified by Moeller et al. (2014). The internal transcribed spacer (ITS) region of the nuclear ribosomal RNA genes of each root tip was amplified using the ITS-1F (Gardes and Bruns 1993) and ITS-4 primers (White et al. 1990), and sequenced by Beckman Coulter Genomics (Danvers, Massachusetts, USA). 
Sequences were clustered into operational taxonomic units (OTUs) using Geneious (Version 5.3.6, Biomatters, Auckland, New Zealand) at $97 \%$ sequence similarity. Because the $97 \%$ sequence similarity threshold has been shown to be a reasonable approximation for fungal species (Smith et al. 2007, Lekberg et al. 2014), we refer to these OTUs as species. Identity of OTUs was assigned by comparing OTU sequences to the GenBank database (Benson et al. 2005) using the Basic Local Alignment And Search Tool (BLAST; available online). ${ }^{5} \mathrm{We}$ considered a match to be at species level if the percent homology was $>97 \%$; all sequences had $>95 \%$ query coverage against the best match. Based on taxonomic assignment we screened our taxa to remove nonectomycorrhizal taxa based on Comandini et al. (2012). We then used the NZFungi database (available online), ${ }^{6}$ the GenBank reported location of the closest matching sequence, and lists of Fuscospora-associated fungi (McKenzie et al. 2000, Orlovich and Cairney 2004) to determine whether a fungus was native to New Zealand.

All statistical analyses were performed using $\mathrm{R}$ version 3.1.0 ( $\mathrm{R}$ Development Core Team 2014). Mycorrhization levels were calculated using both mycorrhizal and non-mycorrhizal seedlings. The percentage of mycorrhizal seedlings was calculated as the percentage of seedlings within each neighborhood context at each site that exhibited $>1$ ectomycorrhizal root tip. Ectomycorrhizal abundance was calculated as the percentage of all seedling root tips (pooled by neighborhood context $\times$ site) that had ectomycorrhizas. Richness was calculated using only mycorrhizal seedlings to avoid confounding presence with richness.

Comparisons of community composition were made using the package vegan (Oksanen et al. 2013). Visualizations of community similarity were made using multidimensional scaling (vegdist; metaMDS), and statistical significance was computed using a permutational MANOVA (adonis). Where significant responses were observed, Tukey's Honestly Significant Difference (HSD) tests were performed to identify statistically significant differences in means. Because root system dry mass (but not number of root tips) increased with seedling age in the field survey (Appendix: Fig. A2), we also used linear models to test for age $\times$ context effects on mycorrhization and fungal community richness. We tested for site effects (Ime; site as random effect), but the inclusion of this random effect did not improve models (AIC values were larger for models with random effects), so site effects are not reported. We also tested for effects of distance from $P$. menziesii plantation (for samples taken in grassland and $F$. cliffortioides neighborhoods), but found no significant effects (data not shown).

\footnotetext{
${ }^{5}$ http://blast.ncbi.nlm.nih.gov

${ }^{6}$ http://nzfungi2.landcareresearch.co.nz/
}

We observed that species richness in the soil bioassay was lower than in the field survey (see Supplement), and that the dominant taxa in the bioassay represented a subset of the taxa present in the field survey. Therefore, we partitioned the field survey data based upon the presence or absence of specific fungal taxa in the bioassay and compared the relative abundances of these two groups of taxa on roots.

\section{ReSUlts}

\section{Presence of ectomycorrhizal fungi}

The majority $(83.1 \%)$ of naturalized P. menziesii seedlings had ectomycorrhizas (ectomycorrhizal fungi present on 344 of 414 seedlings sampled; Fig. 1a), but mean ectomycorrhizal abundance (percentage of root tips having ectomycorrhizas) was lower in $F$. cliffortioides forests $(56.7 \% \pm 2.5 \%$; mean $\pm \mathrm{SE})$ than in grasslands $(79.6 \% \pm 9.4 \%)$ (HSD, $P<0.05$; Fig. 1c). For $F$. cliffortioides forest- and grassland-collected seedlings, spatial distance from the adjacent plantation did not affect mycorrhizal status (linear model, $P>$ 0.05 , results not shown). Mycorrhization increased with seedling age and was consistently greater for seedlings collected from P. menziesii and grassland contexts than from $F$. cliffortioides contexts (best linear model: mycorrhization $\sim$ seedling age + context, $P<0.001$, $R^{2}=0.1081$; Fig. 2a). The linear model uses the coding language, $\mathrm{R}$ (also repeated later in the article), and can be translated, "mycorrhization[/richness] depended upon both seedling age and context, but not their interaction."

Of the 468 experimental seedlings surviving at the end of the greenhouse soil bioassay, $276(58.9 \%)$ had ectomycorrhizas. Control seedlings were clear of mycorrhizas, and experimental seedling mortality was equal across the three ecological contexts. Surviving experimental seedlings grown in soil collected from $P$. menziesii plantations or from grasslands were more likely to form mycorrhizas than seedlings grown in soil collected from $F$. cliffortioides forests (HSD, $P<0.05$; Fig. 1b). Mean ectomycorrhizal abundance was higher on seedlings grown in $P$. menziesii plantation soils $(55.5 \% \pm 1.9 \%)$ than either $F$. cliffortioides forest soils $(10.6 \% \pm 4.6 \%)$ or grassland soils $(23.1 \% \pm 5.8 \%)$ (HSD, $P<0.05$; Fig. 1d). In the greenhouse, we observed mycorrhization differences between groups of seedlings planted in soils collected from either invaded or uninvaded neighborhoods. Ectomycorrhizal abundance was greater on seedlings grown in soils collected from invaded grasslands than seedlings grown in soils from uninvaded grasslands ( $t$ test, $P<0.001$, Fig. 3a).

\section{Richness and composition of ectomycorrhizal fungal communities}

Fungal species richness (number of OTUs, e.g., fungal species) differed among neighborhood contexts. From 344 mycorrhizal field survey seedlings, we sequenced 1920 root tips and obtained 1502 usable sequences 

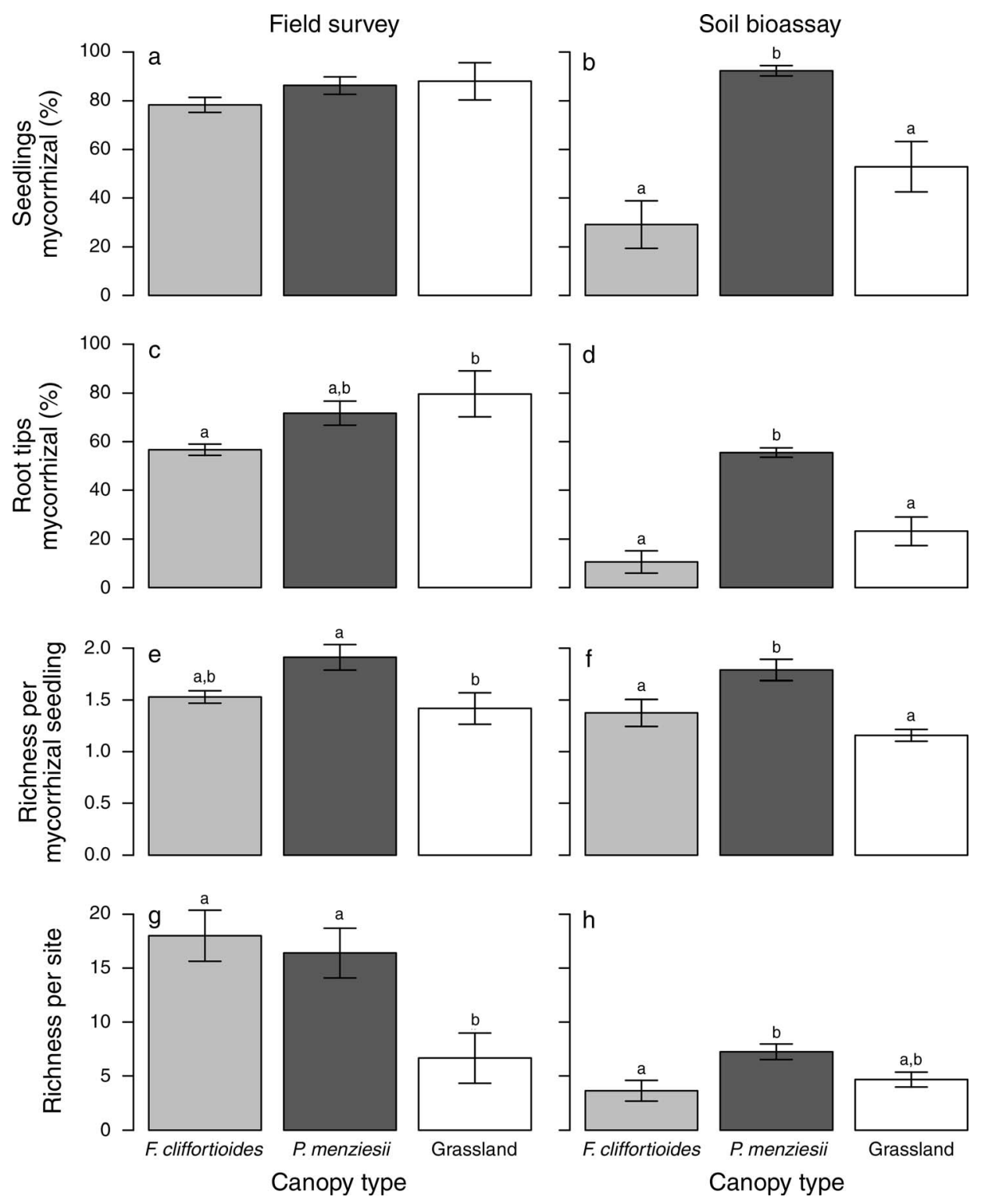

FIG. 1. Fungal mycorrhization levels and richness by neighborhood context for the field survey (left column) and soil bioassay (right column). Bar height represents mean values, and error bars show one standard error above and below the mean. (a, b) Percentage of seedlings that had formed ectomycorrhizas at each site. (c, d) Average percentage of all seedling root tips (i.e., both mycorrhizal and non-mycorrhizal seedlings) that had formed ectomycorrhizas at each site. (e,f) Average species richness on mycorrhizal seedling root systems at each site. $(\mathrm{g}, \mathrm{h})$ Site-level species richness (mycorrhizal seedlings pooled by site). Lowercase letters above the bars indicate statistically significant differences in the mean at the 0.05 level.

(78.2\% success). These sequences clustered into 138 species (see Supplement), of which 78 species (comprising $85.1 \%$ of obtained sequences) were mycorrhizal (Appendix: Fig. A3). Non-mycorrhizal taxa were omitted from further analyses. The most abundant fungal taxa in the field survey were Rhizopogon rogersii, Suillus lakei, and Phialocephala fortinii, which were found in all three neighborhood contexts. Overall, mycorrhizal field-collected seedlings hosted $1.74 \pm 0.05$ ectomycorrhizal fungal species per seedling, with higher richness in $P$. menziesii contexts than grasslands (HSD,
$P<0.05$, Fig. 1e). Site-level richness was greatest when neighborhoods included adult ectomycorrhizal host trees (HSD, $P<0.05$; Fig. 1g). For seedlings collected in $F$. cliffortioides and grassland contexts, seedling distance from the adjacent plantation did not affect fungal species richness (linear model, $P>0.05$, results not shown). Fungal species richness increased with seedling age, and richness at all ages was greater for seedlings collected from $P$. menziesii contexts (best linear model: richness $\sim$ seedling age + context, $P<0.001$, adj. $R^{2}=0.1357$, Fig. 2b). 

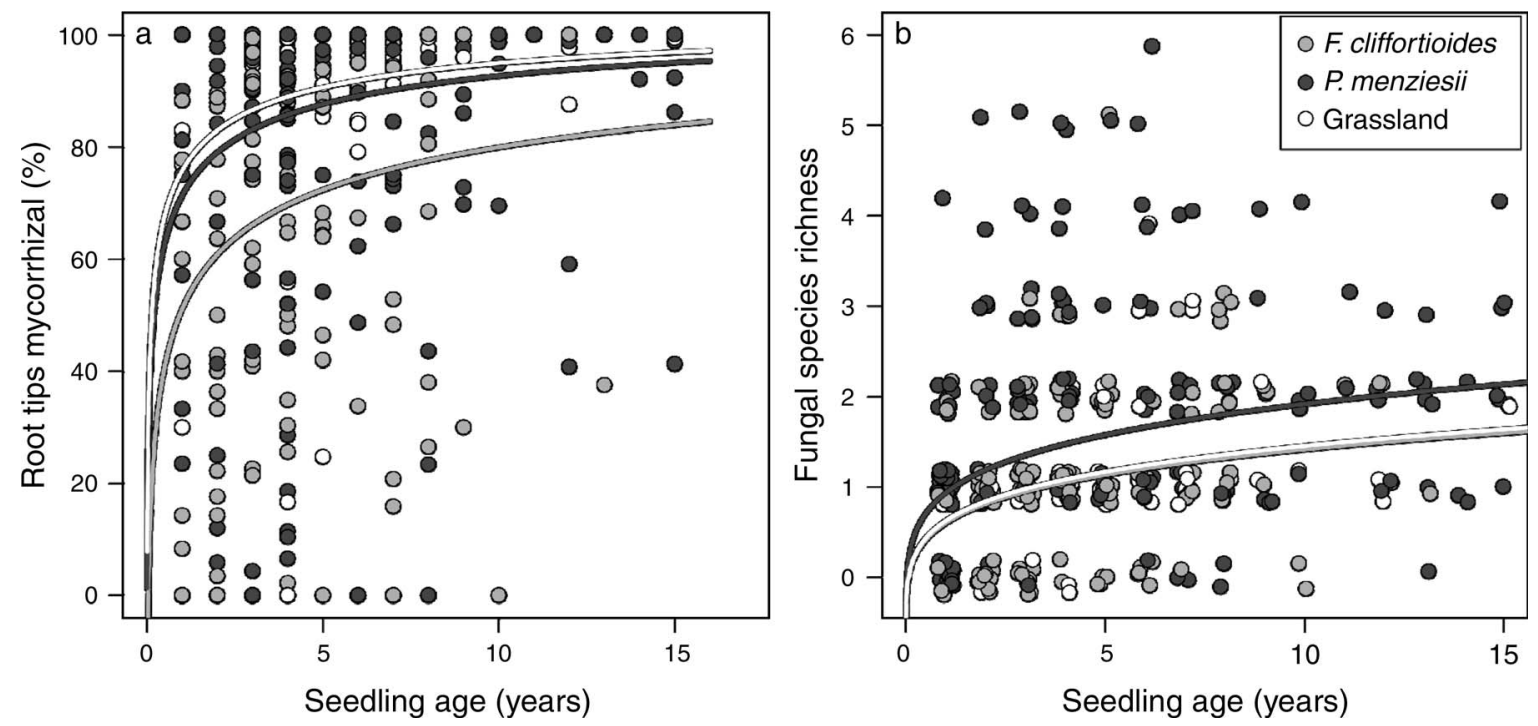

FIG. 2. (a) Increase in mycorrhization levels with increasing field survey seedling age. At all ages, seedlings from $F$. cliffortioides contexts exhibited lower mycorrhization than seedlings from $P$. menziesii and grassland contexts $\left(P<0.001 . R^{2}=0.1081\right)$. (b) Increase in fungal species richness with increasing field survey seedling age. Across ages, seedlings from $P$. menziesii contexts exhibited greater species richness $\left(P<0.001, R^{2}=0.1357\right)$. For both panels, points represent individual seedlings, shaded by context, and lines represent model fits for F. cliffortioides (gray), P. menziesii (black), and grassland (white) contexts. Data points have been jittered for visibility.

From 276 mycorrhizal bioassay seedlings, we sequenced 1883 root tips and obtained 1649 usable sequences $(87.6 \%$ success). These sequences clustered into 82 species (see Supplement), of which 33 species (comprising $84.1 \%$ of obtained sequences) were mycorrhizal (Appendix: Fig. A4). The most abundant fungal taxa were $R$. rogersii, Wilcoxina mikolae, and Cadophora finlandica, which were found in all three contexts. Mycorrhizal seedlings grown in $P$. menziesii plantation soils had up to twofold greater fungal richness than seedlings from other neighborhood contexts (HSD, $P<$ 0.05; Fig. 1f). At the site level, P. menziesii plantation soils had nearly twice the fungal species richness compared with $F$. cliffortioides forest soils (HSD, $P<$ 0.05; Fig. 1h).

Overall, fewer fungal species were found in the soil bioassay than in the field, and the subset of ectomycorrhizal fungi found in the bioassay were dominant only in certain neighborhood contexts in the field (Fig. 3b). For example, of seedlings collected from grasslands, $73.2 \%$ $\pm 4.8 \%$ of all root tips formed mycorrhizas with fungal species that were also identified in the greenhouse, but only $5.3 \% \pm 2.6 \%$ of all root tips formed mycorrhizas with fungi absent from the greenhouse ( $t$ test, $P<$ $0.001)$; the remaining $21.5 \%$ of root tips had no mycorrhizas. In $P$. menziesii plantations, invasive seedlings formed almost twice as many associations with fungal species present in the greenhouse than with species absent from the greenhouse $(43.3 \% \pm 2.9 \%$ vs. $28.8 \% \pm 2.6 \%$ of all seedling root tips; $t$ test, $P<0.001)$. However, there was no difference in mycorrhization rates among seedlings collected from $F$. cliffortioides forests.

Ectomycorrhizal community composition also differed among neighborhoods. The makeup of the most abundant fungal taxa differed across neighborhood contexts (Appendix: Fig. A5). For example, in the field survey, Cortinarius elaiochros, an endemic species that was the fifth most abundant taxon on seedlings collected from $F$. cliffortioides forests, was absent from grassland contexts (Appendix: Figs. A3, A5). In the greenhouse bioassay, Thelephora terrestris, the most abundant fungus on seedlings planted in $F$. cliffortioides soils, was not observed in grassland soils, whereas Tomentella ellisii was found in grassland and P. menziesii contexts, but not in F. cliffortioides soils. Field-collected ectomycorrhizal communities from the same neighborhood context were more similar to each other (reduced BrayCurtis distance) than communities from other neighborhoods, regardless of site (perMANOVA, $F=2.567$, $P=0.001$; Fig. 4a). Similarly, bioassay communities clustered by neighborhood context, rather than by site (perMANOVA, $F=5.068, P=0.001$; Fig. $4 b$ ). The composition of communities from invaded sites was also distinct from communities from uninvaded sites (perMANOVA, $F=2.564, P=0.007)$.

\section{Origins of ectomycorrhizal fungi}

Co-invading ectomycorrhizal fungi were observed across neighborhood contexts and studies (see Supplement), but most native fungi were restricted in their distribution to contexts where native ectomycorrhizal host trees were present. In the field, seedlings were twice 

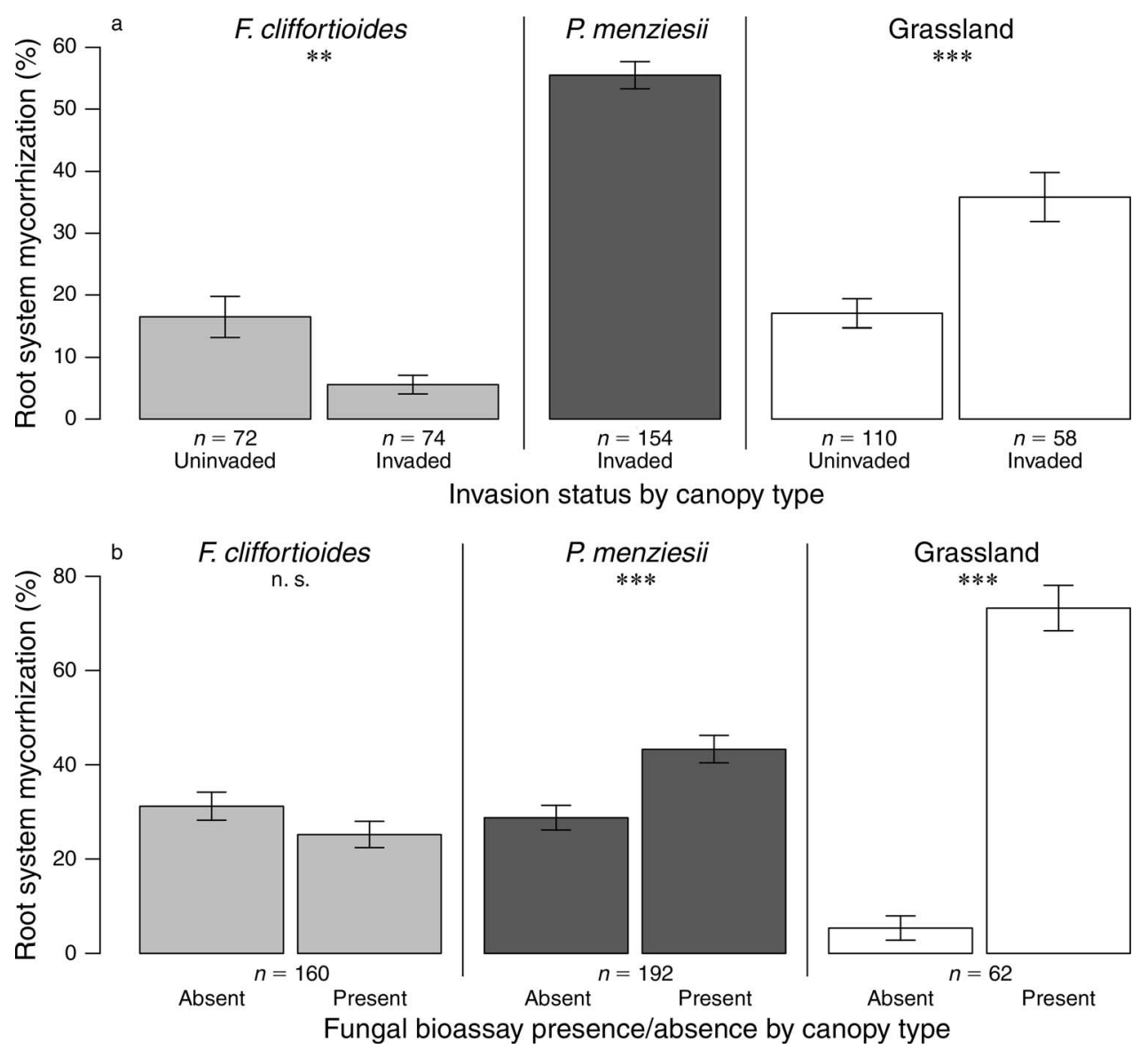

FIG. 3. (a) Effect of site invasion status on mycorrhization of soil bioassay seedlings. In the greenhouse, mycorrhization was lower when seedlings were planted in soils collected from $F$. cliffortioides forests with established Pseudotsuga menziesii seedlings compared to uninvaded forests, but higher in invaded grasslands than uninvaded grasslands. (b) Field survey seedling mycorrhization by fungal taxa that were also present in the soil bioassay (right-hand bars), and by taxa that were absent (left-hand bars) from the soil bioassay. Seedlings invading into $P$. menziesii plantations and grasslands tended to associate with the same fungi that appeared in the soil bioassay. For both panels, bar height represents mean values, and error bars show \pm 1 SE. Significant differences between treatments are shown: ** $P<0.01 ; * * * P<0.001$.

as likely to form mycorrhizas with native fungi in native F. cliffortioides forests as in other neighborhood contexts (HSD, $P<0.05$; Fig. 5a), and the abundance of these mycorrhizas on field-collected seedling root systems was also higher in native forests (HSD, $P<$ 0.001 ; Fig. 5b). Some seedlings exhibited high and exclusive mycorrhizal development by native fungi (Fig. $5 b)$. In the soil bioassay, native fungi were absent across all neighborhood contexts, except for three widely distributed ectomycorrhizal fungi also known to be present in $P$. menziesii's native range: Phialocephala fortinii, Cenococcum geophilum, and Chloridium paucisporum (Wilcox and Wang 1987). Overall, $24 \% \pm 6 \%$ of bioassay seedlings formed at least one ectomycorrhiza with one of these three native fungi, but these natives comprised on average only $3.5 \% \pm 0.7 \%$ of root tip mycorrhizas. There was no difference in the distribution of these three taxa across neighborhood contexts.

\section{Discussion}

Our results demonstrate that diverse, novel symbioses occur between invasive plants and fungi, and that these associations depend on neighborhood context. Specifically, the presence, composition, and origin of ectomycorrhizal fungal associated with the invasive Douglas-fir (Pseudotsuga menziesii) are each influenced by the neighborhood being invaded. In contrast to previous studies suggesting that the invasion success of Pinus, Alnus, and Salix depend largely on co-invading fungi (Nuñez et al. 2009, Dickie et al. 2010, Bogar et al. 2015), we observed a richer array of interactions including coinvasion, cosmopolitan associations, and novel associations of invasive P. menziesii with endemic New Zealand ectomycorrhizal fungi. These findings suggest that biological invasions must be studied under multiple ecological contexts to understand the relative importance of co-invasion and novel interactions in invasions. 

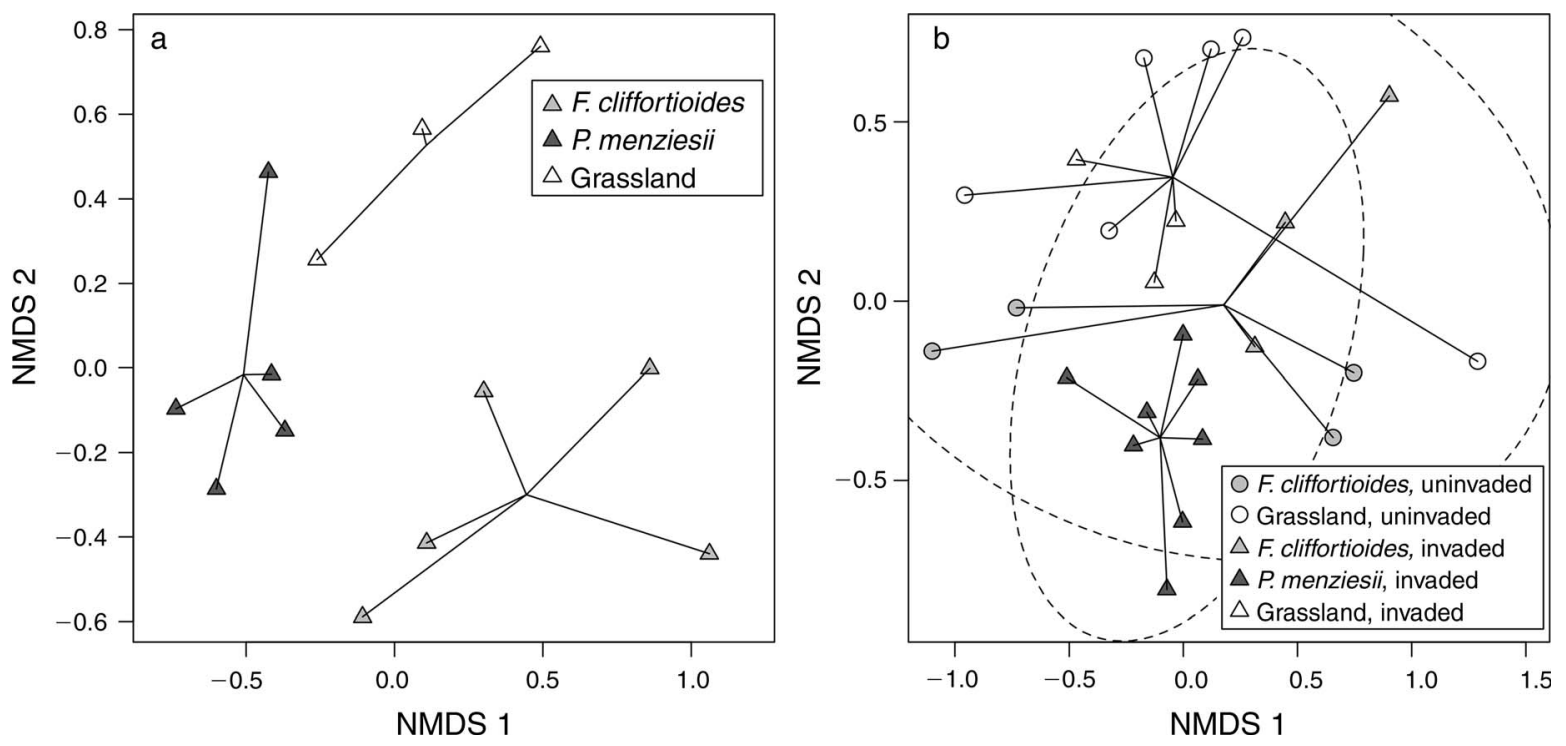

FIG. 4. Bray-Curtis dissimilarity index, based on nonmetric multidimensional scaling plots. In panel (a), each of the 13 data points represents a context $\times$ site combination from the seedling field survey, with seedling data from that location pooled for visualization. Gray points represent F. cliffortioides canopy locations; black points, P. menziesii; and white points, grassland. Distance between points indicates community dissimilarity, with more distant points representing more divergent communities. (b) Soil bioassay community composition, pooled by context $\times$ site. Shading indicates neighborhood context (as in panel a), and shape indicates invasion status (circles indicate no established $P$. menziesii seedlings found at that site; triangles indicate established $P$. menziesii found). Note clustering by invasion status, highlighted by $90 \%$ confidence interval ellipses (dashed lines). The smaller ellipse applies to invaded sites (triangles), and the larger (partial) ellipse to uninvaded sites (circles).
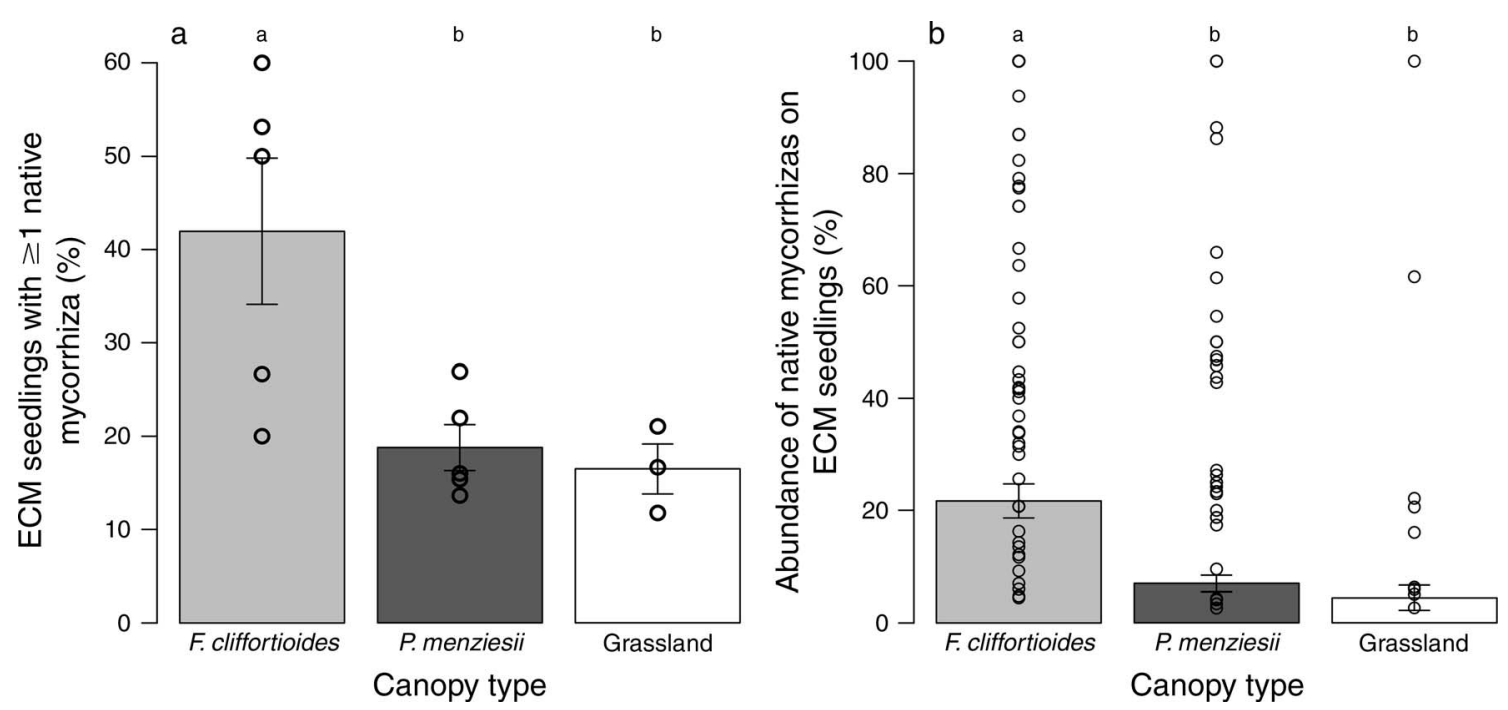

FIG. 5. Presence of native fungi on established $P$. menziesii seedlings collected during the field survey. Bar height represents mean values, and error bars show $\pm \mathrm{SE}$. (a) The percentage of ectomycorrhizal seedlings (i.e., seedlings with at least one ectomycorrhizal root tip) with native colonization (i.e., at least one native-mycorrhized tip) at each site depended upon neighborhood context. Seedlings collected from native $F$. cliffortioides forests were more likely to have at least one association with a native fungi. The data points show percentages for each of the five sampling sites. (b) Native fungus abundance (i.e., percentage of all mycorrhizal seedling root tips mycorrhized by native fungi) was also higher on seedlings collected from native $F$. cliffortioides forests. Data points show native mycorrhization levels of individual seedlings; note the high $(>90 \%)$ abundance in some cases. Lowercase letters above the bars indicate statistically significant differences in the mean at the 0.05 level. 


\section{Presence of ectomycorrhizal fungi}

Our first hypothesis that $P$. menziesii seedlings are fungus limited in grasslands was not supported by the field data, which showed high levels of mycorrhization across all neighborhoods. In contrast, relatively low ectomycorrhization of bioassay seedlings grown in soils from under $F$. cliffortioides compared to seedlings grown in either the grassland or plantation soil suggests that fungal limitation can occur in some contexts. Further, the higher level of mycorrhization in seedlings planted in invaded (relative to uninvaded) grassland soils suggests that the absence of available ectomycorrhizal fungi may limit the initial seedling invasion of New Zealand grasslands, but become less limiting as the invasion progresses. A previous greenhouse bioassay of soils collected from native shrublands found declining mycorrhization rates for $P$. menziesii as distance to mature stands increased, suggesting that fungal limitation may be more significant when sources of inoculum are distant (Davis and Smaill 2009). However, this effect may not occur at the spatial scale of invasion considered here (i.e., <1 km, see, e.g., Hynson et al. [2013]), and may diminish with increasing plantation age because of cumulative deposition of fungal spores into adjacent neighborhoods (Glassman et al. 2015).

Differences between our field and bioassay results reflect the environmental and life-history factors governing the plant-fungal symbiosis. First, the field survey sampled older seedlings (mean age, 4.8 years) compared to the bioassay ( $<1$ year), and older seedlings are likely to accumulate ectomycorrhizas with time (Dickie et al. 2002). Indeed, in our study, older seedlings had greater levels of mycorrhization, as well as greater fungal species richness. Mycorrhizal seedlings may also be easier to detect, as non-mycorrhizal seedlings would likely be smaller in size. Second, there is a survivorship bias in measuring ectomycorrhizas on established plants. That is, seedlings lacking mycorrhizal partners in the field would have a higher probability of mortality, filtering out seedlings lacking ectomycorrhizas (but see Collier and Bidartondo 2009). Third, there was a strong location bias in field sampling, such that only locations where Pseudotsuga had already established could be sampled. The greenhouse bioassay suggests that, at least in the case of grasslands, these previously invaded sites had higher ectomycorrhizal inoculum levels than uninvaded sites. Fourth, and likely of particular relevance in the $F$. cliffortioides context, some mycorrhizal fungi may only associate with seedlings when already supported by established plants ("late-stage" fungi [Deacon et al. 1983]). Finally, other greenhouse conditions may have reduced the probability or extent of seedling mycorrhization.

\section{Richness and composition of fungal community}

Our results partially supported our hypothesis that ectomycorrhizal fungal communities associated with $P$. menziesii differ in richness according to neighborhood context, and supported our hypothesis that composition varies by neighborhood. On field-collected mycorrhizal seedlings, per-seedling fungal community richness was within the range of observed richness on $P$. menziesii seedlings in other systems (Jones et al. 1997). Greater richness in the context of $P$. menziesii plantation soils may indicate greater fungal availability and diversity that has accumulated over the decades following plantation establishment (Davis et al. 1996), particularly including fungi compatible with $P$. menziesii seedlings. Multiple factors may have produced the observed differences in richness and composition across neighborhood contexts. First, adult trees act as a reservoir of fungal inoculum, which can then be transferred to establishing seedlings (Jones et al. 1997, Simard et al. 1997, Bogar and Kennedy 2013). Second, large, established stands of mature trees may host distinct fungal communities compared to isolated trees (Peay et al. 2010, Hynson et al. 2013) and seedlings (Dickie and Reich 2005) due to differences in fungal dispersal (Peay et al. 2010) and successional stage (Deacon et al. 1983).

Both field and greenhouse studies showed significant differences in fungal community composition by neighborhood context. However, the fungal communities identified in the field and bioassay were distinct. The subset of fungi identified in the soil bioassay was dominated by nonnative members of the genera Rhizopogon and Wilcoxina, many of which are wellknown spore colonizers (Castellano and Trappe 1985, Berch and Roth 1993, Visser 1995, Baar et al. 1999, Yu et al. 2001) that do not require the presence of adult trees to form mycorrhizas on seedlings ("early-stage" fungi; Deacon et al. [1983]). Other studies that combined field and greenhouse bioassays have revealed similar taxonomic partitioning (Deacon et al. 1983, Pilz and Perry 1984, Simard et al. 1997, Taylor and Bruns 1999). For example, Amanita and Russula (dominant coinvading genera in our seedling survey that were absent in the soil bioassay) may depend upon a carbon supply from adult host trees for mycorrhization success (Simard et al. 1997, Taylor and Bruns 1999, Cline et al. 2005, Ashkannejhad and Horton 2006). Partitioning the field survey data according to presence in the soil bioassay showed that "early-stage" seedling-compatible fungi are likely to be particularly important at grassland invasion fronts. These taxa are also dominant in $P$. menziesii plantations, where many of them may have been initially introduced to New Zealand to improve seedling growth (Davis et al. 1996).

\section{Origins of ectomycorrhizal fungi}

While the dominant fungal taxa observed were nonnative co-invading fungi from the native range of P. menziesii (Trappe 1962, Molina et al. 1992), a significant proportion of field-collected seedlings exhibited mycorrhization by native New Zealand ectomycorrhizal fungi (Fig. 4). Some of these mycorrhizas 
represented novel associations, including partnerships with endemic ectomycorrhizal fungi associated with Fuscospora that have not previously been observed on invasive ectomycorrhizal plant species (Dickie et al. 2010).

Novel associations between invasive seedlings and native fungi were most common in $F$. cliffortioides neighborhoods; this is consistent with previous work on Fuscospora-associated fungi suggesting that they may depend upon an abundant host carbon supply to successfully establish mycorrhizas on new root systems (Baylis 1980, Dickie et al. 2012). Novel associations between nonnative planted trees and native fungi have been previously observed (Parladé et al. 1995, Jairus et al. 2011, Trocha et al. 2012, Bahram et al. 2013), though not for P. menziesii in New Zealand (Chu-Chou and Grace 1987), but no prior studies of invasive trees have found novel associations with endemic ectomycorrhizal fungi (Dickie et al. 2010, Nuñez and Dickie 2014, Bogar et al. 2015). Novel associations in P. menziesii may, in part, reflect the tree's broad receptivity to a diverse range of fungi. However, the context dependence of novel associations and the absence of novel associations in the greenhouse suggest that associations formed on invasive $P$. menziesii seedlings depend on an abundant carbon supply from neighboring $F$. cliffortioides trees. As such, novel associations may be a reflection of the high shade tolerance of $P$. menziesii, and its consequent ability to invade into intact native forests, rather than the result of a difference in symbiont specificity per se. Although mature plantation $P$. menziesii root systems were not sampled in this study, the presence of native fungi on several seedlings collected in $P$. menziesii plantations, and the absence of endemic native fungi in the soil bioassay (Wilcox and Wang 1987), suggest that these endemic fungi may also have successfully transferred to adult $P$. menziesii host trees.

\section{Implications for invasion of $\mathrm{P}$. menziesii}

Tree seedlings can survive for several years without ectomycorrhizal partners (Collier and Bidartondo 2009), but their growth is typically slowed or halted, which may reduce their competitive ability and consequently the speed of invasion. Nonetheless, where seedlings can survive, our results suggest that they accumulate fungal partners over time, increasing the probability that a mutualistic partner will arrive (Dickie et al. 2002). In forests, the formation of ectomycorrhizal partnerships appears to be facilitated by common mycorrhizal networks, whereas in grasslands, where these networks are absent, associations are formed primarily with sporebased colonists.

Our results suggest that fungi from $P$. menziesii's native range can be patchily distributed. At $P$. menziesii's invasion front, this patchy distribution may reduce the ability of seedlings to establish mutualistic partnerships or cause them to rely on novel interactions with coinvading or native fungi. However, we did not test if the novel partnerships were mutually beneficial. It remains unclear whether native fungi act as facilitators of the $P$. menziesii invasion, or as inhibitors by parasitizing $P$. menziesii root systems.

\section{Conclusions}

We have shown here that neighborhood context, particularly the presence of adult ectomycorrhizal host trees, influences the presence and composition of ectomycorrhizal communities found on invasive Pseudotsuga menziesii seedlings in New Zealand. Adult ectomycorrhizal trees appear to facilitate mycorrhization by late-successional ectomycorrhizal fungi and novel associations with endemic New Zealand taxa. These fungi, in turn, may facilitate the successful naturalization of invasive $P$. menziesii in New Zealand grasslands and forests. Our findings suggest that understanding the dependence of these interactions on neighborhood context can be critical to predicting variation along invasion fronts.

\section{ACKNOWLEDGMENTS}

Field assistance was provided by Kathryn Affeld, Jessica Baker, Helena Ponstein, and Katie Spellman. We thank Nicola Bolstridge, Karen Boot, Joshua Heenan, Thomas Parkes, and Gaye Rattray for help in the greenhouse and the laboratory. We thank Kevin Arrigo, Matthew Knope, Kabir Peay, Jennifer Talbot, Rachel Vannette, Peter Vitousek, the Peay and Fukami lab groups, and two anonymous reviewers for helpful discussion and comments on the manuscript. Financial support was provided by the Core funding for Crown Research Institutes from the New Zealand Ministry of Business, Innovation and Employment's Science and Innovation Group and by Stanford University. H. V. Moeller acknowledges funding from an NSF Graduate Research Fellowship, an NSF Doctoral Dissertation Improvement Grant, and an ARCS Fellowship.

\section{Literature Cited}

Ashkannejhad, S., and T. R. Horton. 2006. Ectomycorrhizal ecology under primary succession on coastal sand dunes: interactions involving Pinus contorta, suilloid fungi and deer. New Phytologist 169:345-354.

Avis, P. G., D. J. McLaughlin, B. C. Dentinger, and P. B. Reich. 2003. Long-term increase in nitrogen supply alters above- and below-ground ectomycorrhizal communities and increases the dominance of Russula spp. in a temperate oak savanna. New Phytologist 160:239-253.

Baar, J., T. Horton, A. M. Kretzer, and T. Bruns. 1999. Mycorrhizal colonization of Pinus muricata from resistant propagules after a stand-replacing wildfire. New Phytologist 143:409-418.

Bahram, M., U. Kõljalg, P. Kohout, S. Mirshahvaladi, and L. Tedersoo. 2013. Ectomycorrhizal fungi of exotic pine plantations in relation to native host trees in Iran: evidence of host range expansion by local symbionts to distantly related host taxa. Mycorrhiza 23:11-19.

Baylis, G. T. S. 1980. Mycorrhizas and the spread of beech. New Zealand Journal of Ecology 3:151-153.

Benson, D. A., I. Karsch-Mizrachi, D. J. Lipman, and D. L. Wheeler. 2005. GenBank. Nucleic Acids Research 33:D34D38.

Berch, S. M., and A. L. Roth. 1993. Ectomycorrhizae and growth of Douglas-fir seedlings preinoculated with Rhizopogon vinicolor and outplanted on eastern Vancouver Island. Canadian Journal of Forest Research 23:1711-1715. 
Bogar, L. M., I. A. Dickie, and P. G. Kennedy. 2015. Testing the co-invasion hypothesis: ectomycorrhizal fungal communities on Alnus glutinosa and Salix fragilis in New Zealand. Diversity and Distributions 21:268-278.

Bogar, L. M., and P. G. Kennedy. 2013. New wrinkles in an old paradigm: neighborhood effects can modify the structure and specificity of Alnus-associated ectomycorrhizal fungal communities. FEMS Microbiology Ecology 83:767-777.

Castellano, M. A., and J. M. Trappe. 1985. Ectomycorrhizal formation and plantation performance of Douglas-fir nursery stock inoculated with Rhizopogon spores. Canadian Journal of Forest Research 5:1-5.

Chu-Chou, M., and L. J. Grace. 1987. Mycorrhizal fungi of Pseudotsuga menziesii in the South Island of New Zealand. Soil Biology and Biochemistry 19:243-246.

Cline, E. T., J. F. Ammirati, and R. L. Edmonds. 2005. Does proximity to mature trees influence ectomycorrhizal fungus communities of Douglas-fir seedlings? New Phytologist 166: 993-1009.

Collier, F. A., and M. I. Bidartondo. 2009. Waiting for fungi: the ectomycorrhizal invasion of lowland heathlands. Journal of Ecology 97:950-963.

Comandini, O., A. C. Rinaldi, and T. W. Kuyper. 2012. Measuring and estimating ectomycorrhizal fungal diversity: a continuous challenge. Pages 165-200 in M. Pagano, editor. Mycorrhiza: occurrence in natural and restored environments. Nova Science Publishers, New York, New York, USA.

Davis, M., and S. Smaill. 2009. Mycorrhizal colonisation of exotic conifers in kānuka and mānuka shrublands. New Zealand Journal of Ecology 33:147-155.

Davis, M. R., L. J. Grace, and R. F. Horrell. 1996. Conifer establishment in South Island high country: influence of mycorrhizal inoculation, competition removal, fertiliser application, and animal exclusion during seedling establishment. New Zealand Journal of Ecology 26:380-394.

Deacon, J. W., S. J. Donaldson, and F. T. Last. 1983. Sequences and interactions of mycorrhizal fungi on birch. Plant and Soil 71:257-262

Dickie, I., M. Davis, and F. Carswell. 2012. Quantification of mycorrhizal limitation in beech spread. New Zealand Journal of Ecology 36:210.

Dickie, I., and P. B. Reich. 2005. Ectomycorrhizal fungal communities at forest edges. Journal of Ecology 93:244-255.

Dickie, I. A., N. Bolstridge, J. A. Cooper, and D. A. Peltzer. 2010. Co-invasion by Pinus and its mycorrhizal fungi. New Phytologist 187:475-484.

Dickie, I. A., B. Xu, and R. T. Koide. 2002. Vertical niche differentiation of ectomycorrhizal hyphae in soil as shown by T-RFLP analysis. New Phytologist 156:527-535.

Essl, F., D. Moser, S. Dullinger, T. Mang, and P. E. Hulme. 2010. Selection for commercial forestry determines global patterns of alien conifer invasions. Diversity and Distributions 16:911-921.

Fleming, L. V. 1983. Succession of mycorrhizal fungi on birch: infection of seedlings planted around mature trees. Plant and Soil 71:263-267.

Froude, V. A. 2011. Wilding conifers in New Zealand: Status Report. Ministry of Agriculture and Forestry, Auckland, New Zealand.

Gardes, M., and T. D. Bruns. 1993. ITS primers with enhanced specificity for basidiomycetes - application to the identification of mycorrhizae and rusts. Molecular Ecology 2:113-118.

Glassman, S. I., K. G. Peay, J. M. Talbot, D. P. Smith, J. A. Chung, J. W. Taylor, R. Vilgalys, and T. D. Bruns. 2015. A continental view of pine-associated ectomycorrhizal fungal spore banks: a quiescent functional guild with a strong biogeographic pattern. New Phytologist 205:1619-1631.
Hallett, S. G. 2006. Dislocation from coevolved relationships: a unifying theory for plant invasion and naturalization? Weed Science 54:282-290.

Hayward, J., T. R. Horton, A. Pauchard, and M. A. Nuñez. 2015. A single ectomycorrhizal fungal species can enable a Pinus invasion. Ecology 96. http://dx.doi.org/10.1890/ 14-1100.1

Heenan, P. B., and R. D. Smissen. 2013. Revised circumscription of Nothofagus and recognition of the segregate genera Fuscospora, Lophozonia, and Trisyngyne (Nothofagaceae). Phytotaxa 146:1-31.

Horton, T., T. Bruns, and V. Parker. 1999. Ectomycorrhizal fungi associated with Arctostaphylos contribute to Pseudotsuga menziesii establishment. Canadian Journal of Botany 77:93-102.

Hynson, N. A., V. S. F. T. Merckx, B. A. Perry, and K. K. Treseder. 2013. Identities and distributions of the co-invading ectomycorrhizal fungal symbionts of exotic pines in the Hawaiian Islands. Biological Invasions 15:2373-2385.

Jairus, T., R. Mpumba, S. Chinoya, and L. Tedersoo. 2011. Invasion potential and host shifts of Australian and African ectomycorrhizal fungi in mixed eucalypt plantations. New Phytologist 192:179-187.

Jones, M., D. Durall, S. Harniman, D. Classen, and S. Simard. 1997. Ectomycorrhizal diversity on Betula papyrifera and Pseudotsuga menziesii seedlings grown in the greenhouse or outplanted in single-species and mixed plots in southern British Columbia. Canadian Journal of Forest Research 27: 1872-1889.

Lekberg, Y., S. M. Gibbons, and S. Rosendahl. 2014. Will different OTU delineation methods change interpretation of arbuscular mycorrhizal fungal community patterns? New Phytologist 202:1101-1104.

Marx, D. H. 1972. Ectomycorrhizae as biological deterrents to pathogenic root infections. Annual Review of Phytopathology 10:429-454.

McKenzie, E., P. Buchanan, and P. Johnston. 2000. Checklist of fungi on Nothofagus species in New Zealand. New Zealand Journal of Botany 38:635-720.

Moeller, H. V., K. G. Peay, and T. Fukami. 2014. Ectomycorrhizal fungal traits reflect environmental conditions along a coastal California edaphic gradient. FEMS Microbiology Ecology 87:797-806.

Molina, R., H. Massicotte, and J. Trappe. 1992. Specificity phenomena in mycorrhizal symbioses: community-ecological consequences and practical implications. Pages 357-423 in M. Allen, editor. Mycorrhizal functioning: an integrative plant-fungal process. Chapman and Hall, New York, New York, USA.

Nara, K. 2006. Ectomycorrhizal networks and seedling establishment during early primary succession. New Phytologist 169:169-178.

Nara, K., and T. Hogetsu. 2004. Ectomycorrhizal fungi on established shrubs facilitate subsequent seedling establishment of successional plant species. Ecology 85:1700-1707.

Newman, E. I. 1988. Mycorrhizal links between plants: their functioning and ecological significance. Pages 243-270 in Advances in ecological research. Academic Press, San Diego, California, USA.

Nuñez, M. A., and I. A. Dickie. 2014. Invasive belowground mutualists of woody plants. Biological Invasions 16:645-661.

Nuñez, M. A., T. Horton, and Daniel Simberloff. 2009. Lack of belowground mutualisms hinders Pinaceae invasions. Ecology 90:2352-2359.

Oksanen, J., F. G. Blanchet, R. Kindt, P. Legendre, P. R. Minchin, B. O'Hara, G. L. Simpson, P. Solymos, M. H. H. Stevens, and H. Wagner. 2013. July 12. vegan: Community Ecology Package. R package version 2.0-10. R Foundation for Statistical Computing, Vienna, Austria. 
Orlovich, D., and J. Cairney. 2004. Ectomycorrhizal fungi in New Zealand: current perspectives and future directions. New Zealand Journal of Botany 42:721-738.

Parladé, J., I. Alvarez, and J. Pera. 1995. Ability of native ectomycorrhizal fungi from northern Spain to colonize Douglas-fir and other introduced conifers. Mycorrhiza 6: $51-55$.

Peay, K. G., M. Garbelotto, and T. D. Bruns. 2010. Evidence of dispersal limitation in soil microorganisms: isolation reduces species richness on mycorrhizal tree islands. Ecology 91: 3631-3640.

Perry, G. L. W., J. M. Wilmshurst, and M. S. McGlone. 2014. Ecology and long-term history of fire in New Zealand. New Zealand Journal of Ecology 38:157-176.

Pilz, D., and D. Perry. 1984. Impact of clearcutting and slash burning on ectomycorrhizal associations of Douglas-fir seedlings. Canadian Journal of Forest Research 14:94-100.

Pringle, A., J. D. Bever, M. Gardes, J. L. Parrent, M. C. Rillig, and J. N. Klironomos. 2009. Mycorrhizal symbioses and plant invasions. Annual Review of Ecology, Evolution, and Systematics 40:699-715.

R Development Core Team. 2014. August 24. R: a language and environment for statistical computing. R Foundation for Statistical Computing, Vienna, Austria.

Richardson, D., N. Allsopp, C. D'Antonio, S. Milton, and M. Rejmanek. 2000. Plant invasions-the role of mutualisms. Biological Reviews 75:65-93.

Simard, S., D. Perry, J. Smith, and R. Molina. 1997. Effects of soil trenching on occurrence of ectomycorrhizas on Pseudotsuga menziesii seedlings grown in mature forests of Betula papyrifera and Pseudotsuga menziesii. New Phytologist 136: $327-340$.

Simard, S. W., and D. M. Durall. 2004. Mycorrhizal networks: a review of their extent, function, and importance. Canadian Journal of Botany 82:1140-1165.

Smith, M. E., G. W. Douhan, and D. M. Rizzo. 2007. Intraspecific and intra-sporocarp ITS variation of ectomycorrhizal fungi as assessed by rDNA sequencing of sporocarps and pooled ectomycorrhizal roots from a Quercus woodland. Mycorrhiza 18:15-22.
Spence, L. A., I. A. Dickie, and D. A. Coomes. 2011. Arbuscular mycorrhizal inoculum potential: a mechanism promoting positive diversity-invasibility relationships in mountain beech forests in New Zealand? Mycorrhiza 21: 309-314.

Taylor, D., and T. Bruns. 1999. Community structure of ectomycorrhizal fungi in a Pinus muricata forest: minimal overlap between the mature forest and resistant propagule communities. Molecular Ecology 8:1837-1850.

Trappe, J. M. 1962. Fungus associates of ectotrophic mycorrhizae. Botanical Review 28:538-606.

Trappe, J. M. 1977. Selection of fungi for ectomycorrhizal inoculation in nurseries. Annual Review of Phytopathology 15:203-222.

Trocha, L. K., I. Kałucka, M. Stasińska, W. Nowak, M. Dabert, T. Leski, M. Rudawska, and J. Oleksyn. 2012. Ectomycorrhizal fungal communities of native and nonnative Pinus and Quercus species in a common garden of 35year-old trees. Mycorrhiza 22:121-134.

Visser, S. 1995. Ectomycorrhizal fungal succession in jack pine stands following wildfire. New Phytologist 129:389-401.

White, T. J., T. Bruns, S. Lee, and J. W. Taylor. 1990. Amplification and direct sequencing of fungal ribosomal RNA genes for phylogenetics. Pages 315-322 in M. A. Innis, D. H. Gelfand, J. J. Sninsky, and T. J. White, editors. PCR protocols: a guide to methods and applications. Academic Press, New York, New York, USA.

Wilcox, H. E., and C. Wang. 1987. Mycorrhizal and pathological associations of dematiaceous fungi in roots of 7-month-old tree seedlings. Canadian Journal of Forest Research 17:884-899.

Wood, J. R., I. A. Dickie, H. V. Moeller, D. A. Peltzer, K. I. Bonner, G. Rattray, and J. M. Wilmshurst. 2015. Novel interactions between non-native mammals and fungi facilitate establishment of invasive pines. Journal of Ecology 103: 121-129.

Yu, T., K. Egger, and L. Peterson. 2001. Ectendomycorrhizal associations - characteristics and functions. Mycorrhiza 11: 167-177.

\section{Supplemental Material}

\section{Ecological Archives}

The Appendix and the Supplement are available online: http://dx.doi.org/10.1890/14-2361.1.sm 